\title{
Determining the Relationship between Anime Species Using Apriori Algorithm
}

\author{
Sakir Isleyen \\ Department of Econometrics, Faculty of Economics and Administrative Sciences, \\ Van Yuzuncu Yil University, Van, Turkey \\ E-mail: sakirisleyen@yyu.edu.tr \\ Servet Oksuz \\ Department of Software Engineering, Faculty of Technology, \\ Firat University, Elazig, Turkey \\ E-mail: rdservetoksuz@gmail.com
}

\begin{abstract}
Some of the Anime viewers focus on a particular genre, while some watch more than one type of Anime. In this study, data mining algorithm was used to investigate the extent to which Anime viewers are influenced by individual selection and selection factors based on genre. For this purpose, the collected data were analyzed by using Apriori algorithm, one of the association rule algorithms, which is one of the data mining methods. As a result of the studies, it was found that the relationship between the species followed by genre is close to $100 \%$ and that the results fluctuate between $15-80 \%$ in personal elections.
\end{abstract}

Key words: Data Mining, Association Rule, Apriori, Anime.

DOI: $10.7176 / \mathrm{JSTR} / 5-7-13$

\section{Anime Türleri Arasındaki İlişkinin Apriori Algoritması Kullanılarak Belirlenmesi}

\begin{abstract}
Özet
Anime izleyicilerinin bazıları belli bir tür üzerinde yoğunlaşırken bazıları birden fazla türde Anime izlemektedirler. Bu çalışmada Anime izleyicilerinin, Anime seçimlerinin kişisel seçim ve türe göre olan seçim faktörlerinden hangi oranda etkilendiklerini veri madenciliği algoritması kullanılarak incelenmiş̧tir. Bunun için toplanılan anket verileri veri madenciliği yöntemlerinden birliktelik kuralı algoritmalarından Apriori algoritması kullanılarak incelenmiştir. Yapılan çalışmalar sonucunda türe göre izlenmekte olan Animelerin türleri arasında ilişkinin \%100'e yakın sonuç çıkardığı ve kişisel seçimlerde bu sonuçların \%15-80 arası dalgalanıyor olduğu bulunmuştur.
\end{abstract}

Anahtar Kelimeler: Veri Madenciliği, Birliktelik Kuralı, Apriori, Anime.

1. Giriş

Japon kültürünün bir parçası olan Animeler[1,2], başka bir Japon kültürü olan ve 1970'lerde Japonya'da popüler olan Manga yani Japon yapımı çizgi romanlarla bağlantılıdır. Japon animasyonları ilk olarak 20. yüzyılın başlarında Japon film yapımcılarının Fransa, Almanya, Amerika Birleşik Devletleri, Rusya gibi devletlerdeki animasyon tekniklerini keşfetmeleri ile ortaya çıkmıştır. 1980'lerde ise Mangaların animasyon uyarlamaları için Fransızca Animation kelimesinden türetilmiş Japonca "Anime" kelimesi kullanılmaya başlanmıştır. Animeler ilk olarak Walt Disney'den etkilenerek çizilmeye başlandığı için genel karakter çizimlerinin uzun bacaklı ve büyük gözlü olduğu söylenmektedir. 21. yüzyıl başlarında Anime adı tüm dünya tarafından benimsenmiş bir kavram olmaya başlamıştır. Anime, Türkiye'ye ilk geldiği zamanlarda bazı video satan dükkanların "Anime" yerine hatalı bir kullanım olarak "Manga" kelimesini kullanmaları sebebi ile Anime ve Manga terimlerinde anlam karmaşası yaşanmıştır.[1,2] 
Anime, dünya genelinde tanınan bir kültür hâline gelmiş olup genel olarak her yaştan izleyici hitap etmektedir. Türkiye'de de dünyada olduğu gibi geniş bir izleyici kitlesi bulunmaktadır. Fansub adı altında birçok gönüllü çevirmen grubu Japonca dublaj olan Animeleri kendi ülkelerinin dillerinde alt yazıya çevirme çalışmaları sürdürmektedir. Bazı ülkelerde bazı Animeler ülkenin kendi diline dublaj yapılarak televizyonlarda yayınlanmaktadır.

Animeleri konu alan ve değişik alanlarda yapılmış çalışmalar vardır. Anime ile alakalı bazı çalışmalar şu şekilde siralanabilir; Siberkültürde Bedenin Görsel Sunumu:Serial Experiments Lain Adlı Anime Üzerine Bir Çözümleme[3]. Siberpunk Animasyon Sinemasında Katoptikon İzlekler Anime Film "Serial Experiments Lain" Örneği[4]. Yerelden Evrensele Japon Anime ve Manga Sanat1[5]. Japon Bilim Kurgu Animelerinde Kent ve Mimarlık: Ghost in the Shell I \& II ve Metropolis Animeleri Üzerinden Bir İnceleme[6].

Veri seti üzerinde sırası ile apriori algoritmasını[7] iki farklı yaklaşım ile uyguladık. İlk uyguladığımız apriori algoritmasına, Tek Katmanlı Apriori; ikinci uyguladığımız apriori algoritmasına, İki Katmanlı Apriori adını verdik. Bu iki uygulamaya İkili Apriori adını verdik.

Her satırda bulunan sütunları bir veri grubu olarak kabul ettik ve her satıra ayrı ayrı Tek Katmanlı Apriori uyguladık. Her bir satırdan elde edilen Tek Katmanlı Apriori sonuçlarını ayrı veri grupları olarak kabul ettik ve veriler üzerinde İki Katmanlı Apriori uyguladık. Normal koşullarda her satırda bulunan sütunların bileşimini alarak Apriori Algoritması uygulanır. Ama bulduğumuz sonuçlar mevcut yollarla temizlenemeyen gürültülerden dolayı yüksek güven değeri olduğu halde gerçeği yansıtmamaktadır. İkili Apriori sonucunun düşük güven aralığı olmasına karşın verilerde bulunan gürültüler temizlendiği için daha tutarlı olduğunu bulduk.

Tek aşamalı Apriori akış diyagramı aşağıdaki gibidir.

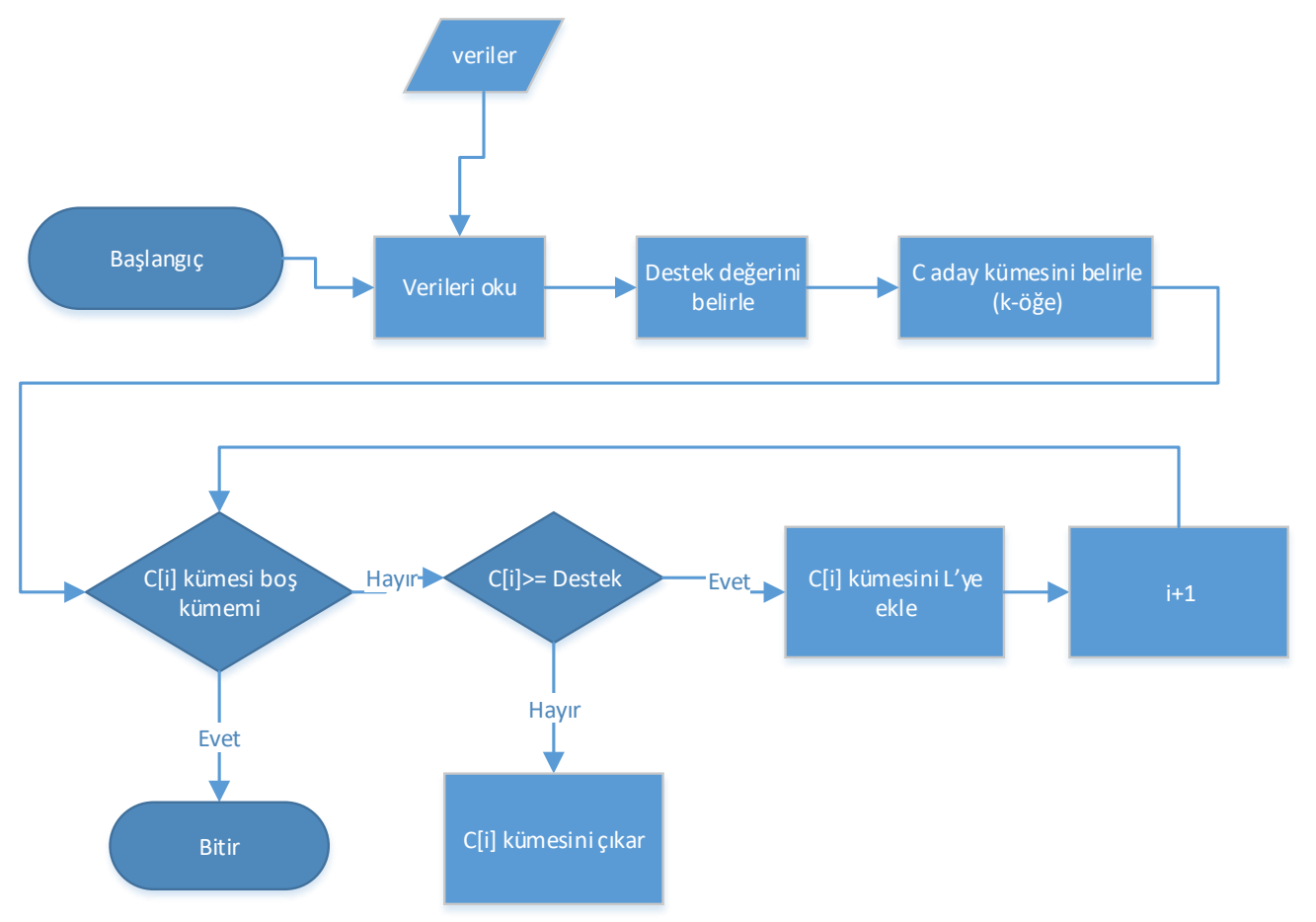


İki aşamalı Apriori akış diyagramı aşağıdaki gibidir.

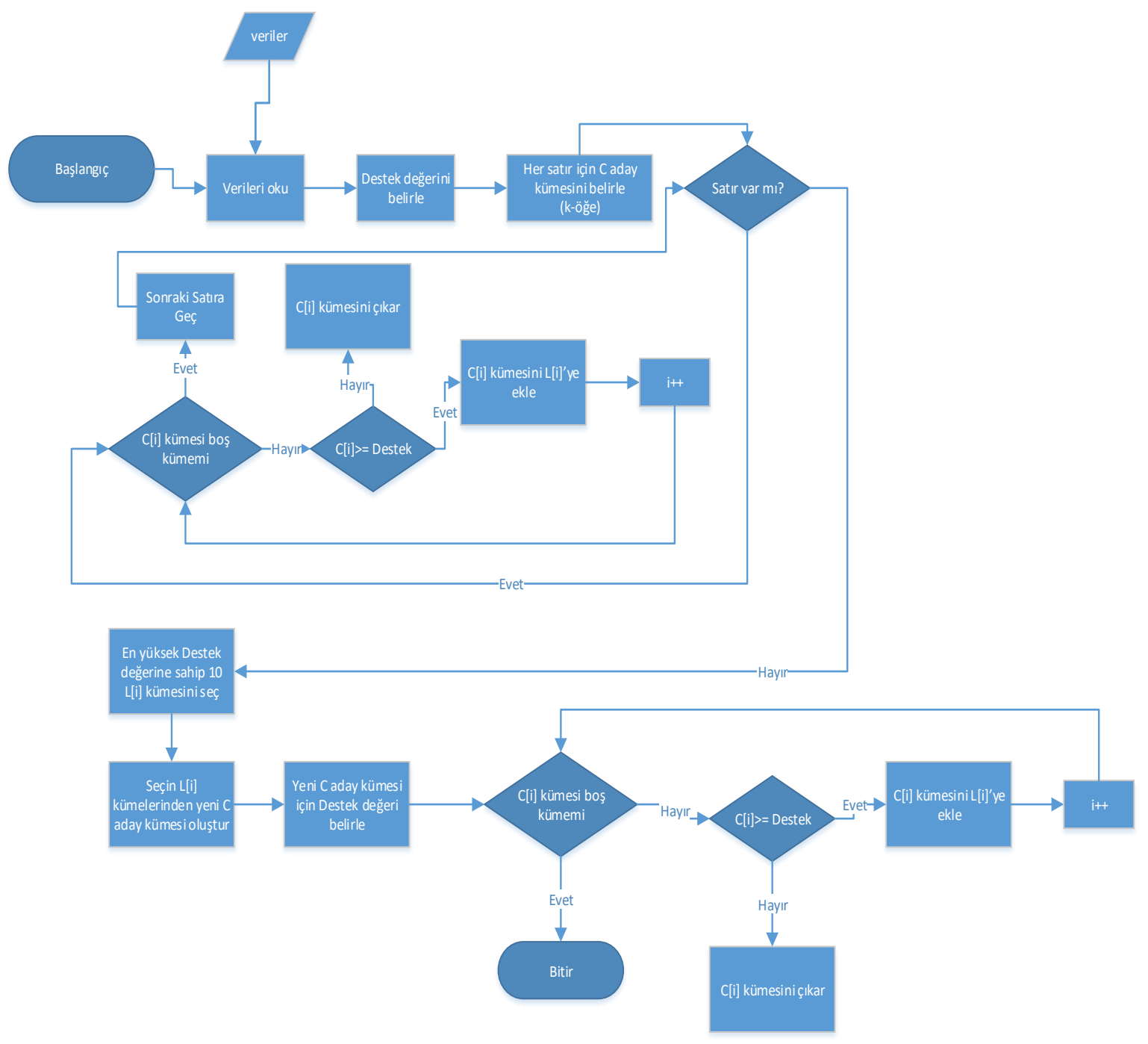

\section{Veri Madenciliği}

Veri madenciliğini[8], en basit tanımı ile eldeki verileri belirli teknikler ile işleyerek elde olmayan verileri tahmin edebilmek ve mevcut duruma dair çıkarımlarda bulunmak olarak tanımlayabiliriz. Veri madenciliği, günümüzde birçok alanda bilgi elde etmek ve çıkarımda bulunmak amacıyla kullanılmaktadır. Veri madenciliğinin kullanıldığı bazı alanlara; finans, pazarlama, ticaret, sağlık, sosyal medyayı örnek olarak verebiliriz[9]. Apriori Algoritması, sınıflandırma, kümeleme, birliktelik kuralları gibi bazı veri madenciliği yöntemlerinden biri olan birliktelik kuralı algoritmalarından biridir. Apriori algoritmasının sözde kodu aşağıdaki gibidir.

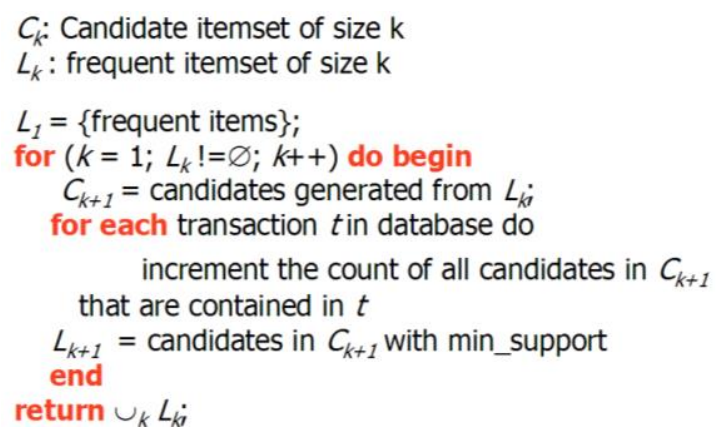


Apriori sözde kodu[10]

$\mathrm{C}$, aday öğe kümemizi ve L, sık geçen k-öğe kümemizi temsil etmektedir. Her C kümesi kendine ait boş küme haricindeki alt kümeleri $\mathrm{C}[1], \mathrm{C}[2] \ldots \mathrm{C}[\mathrm{k}]$ içerir ve k-öğe kümesini oluşturur. C kümelerinde minimum destek koşulunu sağlayan alt küme değerlerini L kümesine ekleyerek sık geçen k-öğe kümesini elde ederiz.[11]

Birliktelik kuralında güven ve destek adı verilen iki ölçütle karşılaşırız.[12] Hesaplanan bu iki ölçütün büyük olmaları sonucun iyi çıktığının bir göstergesi olarak kabul edebiliriz. $(\mathrm{A} \rightarrow \mathrm{B})$ şeklindeki tanımlama, A olayının gerçekleşmesi durumunda B olayının gerçekleşmesi durumu anlamına gelmektedir. Destek değerinin hesabı şu şekildedir:

$$
\text { Destek }=\frac{\operatorname{sayl}(A \rightarrow B)}{N}
$$

Buradaki 'N'yi toplam olay sayısı ve 'sayı $(A \rightarrow B)$ ' ise A olayı olduğunda aynı zamanda B olayının da olma sayısı olarak ele alınabiliriz. Güven değeri ise bir olayın olma olasılığının diğer olaylarla ilişkisini hesaplar. Güven değerinin hesabı şu şekildedir:

$$
\text { Güven }=\frac{\operatorname{sayl}(A \rightarrow B)}{\operatorname{sayl}(A)}
$$

Buradaki 'sayı(A $\rightarrow$ B)' formül 2.1'de bulunan ifade ile aynı anlamdadır, 'sayı(A)' ise A olayının olma sayısı olarak ele alınabilir.

Destek değeri bulunan sonucun veri seti içerisinde hangi oranda tekrarlandığını göstermektedir. Destek değeri, formül 2.1 kullanılarak yüzde değer bulunabileceği gibi sadece 'sayı $(A \rightarrow B)$ ' değeri ile sayısal olarak da kullanılabilmektedir. Genellikle en küçük değer ' 3 ' olarak seçilir. Bu çalışmada Destek değerini ' $\operatorname{say} \iota(A \rightarrow B)$ ' şeklinde kullandık. Destek değerinin altında tekrar oranına sahip veriler gürültü olarak kabul edilir ve temizlenir. Güven değeri ise bulunan veri kümesi içerisindeki verilerin bir birleri ile olan oransal ilişkilerini göstermekte kullanılır.

\section{Uygulama}

Uygulamanın temel amacı, anket katılımcılarının genelde izledikleri Animeler ile türüne göre izledikleri Animeler arasında, apriori algoritması uygulayarak elde edilen oranların hangisinin daha iyi olduğunun tespitini yapmaktır.

Bir katılımcının aksiyon türünde belirttiği Anime aksiyon ve diğer birkaç türden oluşuyor olsun, bu katılımcı macera türünde belirttiği Animeyi içinde aksiyon olduğu için mi izlemektedir yoksa macera olduğu için mi izlemektedir? Aksiyon türündeki belirttiği Anime ile macera türünde belirttiği Animeyi aksiyon türü içerdiği için mi izliyor yoksa izlediği Animenin diğer türleri ankette yer almadığı için mi aksiyon türünde o Animeyi belirtmiştir? Aksiyon türündeki Animeleri izlemeyi sevdiği için mi katılımcının diğer türlerde belirttiği Animelerin bazılarında da aksiyon türü bulunmaktadır?

Uygulama süresince yukarıdakine benzer sorulara cevap arayacağız ve aynı zamanda katılımcıların en çok izledikleri türlerin bir arada bulunduğu Animeleri ne oranda izlediklerini bulacağız. Örneğin; aksiyon türünde Anime izlemeyi sevenlerin aynı zamanda yüzde kaç olasılıkla macera ve okul türünü de içeren yani, aksiyon, macera ve okul, türlerinden oluşan bir Animeyi sevebileceği cevabını bulacağız.

Biraz karmaşık olduğu için olayı bir sepet analizi örneği ile açıklayalım. Örnekte aynı kişilere ait 3 günlük alış verişlerinin tutulduğu tablomuz olsun. Ürün isimleri yerine ürünleri temsilen sayısal içerikler kullandık ve her bir ürün numarası virgül(,) ile ayırdık. Destek değerini 3 olarak seçtik.

\begin{tabular}{|l|l|}
\hline Müşteri No & Alışverişler \\
\hline 1 & $\{\{1,2,3\},\{1,4,5\},\{1,3,6\}\}$ \\
2 & $\{\{5,6,7\},\{1,3,5\},\{2,4,5\}\}$ \\
3 & $\{\{4,5,8\},\{1,6,8\},\{7,8\}\}$ \\
\hline
\end{tabular}

(Tablo 3-1: Örnek sepet tablosu)

Örneğimizde 2. günde 1 numaralı üründe indirim olduğunu var sayalım alalım. Apriori uygularken bir kişiye ait tüm ürünleri tek veri olarak düşünürsek aşağıdaki gibi olur; 


\begin{tabular}{|l|l|}
\hline 1 & $\{1,2,3,4,5,6\}$ \\
2 & $\{1,2,3,4,5,6,7\}$ \\
3 & $\{1,4,5,6,7,8\}$ \\
\hline
\end{tabular}

(Tablo 3-2: Tablo 3-1 verilerinin birleştirilmiş görüntüsü)

Eğer tablo bu hale gelirse 1. müşterinin 1 numaralı ürünü her gün alması ile indirim günü tüm müşterilerin 1 numaralı ürünü alması arasındaki farkı bulamayız. Eğer her bir müşterinin günlük alışverişlerini ayrı bir veri olarak değerlendirelim. Bir 'apriori' sütunu oluşturalım ve içine her bir müşteri için 4.1.1'deki apriori algoritmasında ulaşılan en fazla elemanlı kümeyi yazalım. Son olarak oluşturduğumuz 'apriori' sütunu üzerinde apriori algoritması uygularsak; sadece indirim günü alınan 1 numaralı ürün 'apriori' sütunu üzerinde sadece 1. müşteride bulunacağ 1 için 1 numaralı ürünün oluşturduğu gürültüden kurtulmuş oluruz. Bahsi geçen ‘apriori' sütununu tablo 3-3'te görebilirsiniz.

\begin{tabular}{|l|l|l|}
\hline Müşteri No & Alışverişler & $\begin{array}{l}\text { apriori } \\
\text { (destek koşulunu sağlayan } \\
\text { değerler) }\end{array}$ \\
\hline 1 & $\{\{1,2,3\},\{1,4,5\},\{1,3,6\}\}$ & $\{1\}$ \\
3 & $\{\{5,6,7\},\{1,3,5\},\{2,4,5\}\}$ & $\{5\}$ \\
& $\{\{4,5,8\},\{1,6,8\},\{7,8\}\}$ & $\{8\}$ \\
\hline
\end{tabular}

(Tablo 3-3: Tablo 3-1 için anlatılan ‘apriori’ sütunun eklenmesi)

Sonuç olarak tablo 3-2'de elde edilen verilerin aksine müşteriler tüm ürünleri almadıklarını görmekteyiz. Bunun yerine her bir müşterinin tablo 3-3'teki 'apriori' sütununda belirtilen ürünü alma eğiliminde olduğunu görmekteyiz.

Uygulama adımlarını anlatırken normal apriori algoritması "Tek Katmanlı Apriori”, yukarıda anlatılmış olduğumuz algoritmayı ise "İki Katmanlı Apriori” olarak adlandıracağız.

Anime verilerimizde ise günler yerine Anime türleri gelmiştir ve çalışma mantığı aynıdır. "Tek Katmanlı Apriori” ve "İki Katmanlı Apriori”" algoritmaları ile ilgili olarak sırasıly başlık 3.2.1 ve 3.2.2'de uygulama adımlarını kısaca anlatmaktayız. Başlık 4.3'te uygulama sonucu elde ettiğimiz sayısal verilerin tablolarına yer vermiş bulunmaktayız.

\subsection{Veri Seti Tanıtımı, Gürültü Temizleme ve Veri Dönüștürme}

Google anket uygulaması ile hazırlanan ankette turkanime.tv internet sitesi üzerinden Şubat 2017 tarihinde tablo 3-1'de verilen 16 türdeki en çok beğeni oyu almış ilk 5 Animeden hangisinin daha iyi olduğu ve katılımcıların yaşlarını sorduk. Anket facebook sosyal paylaşım sitesinde bulunan bazı Anime hayran sayfalarında paylaşarak yaklaşık 320 veri topladık. Anket verilerinde bulunan gürültüler temizlendikten sonra elimizde 196 veri kalmıştır.

\begin{tabular}{|l|l|}
\hline \multicolumn{2}{|c|}{ (Tablo 3-1: Ankette sorulan Anime türleri) } \\
\hline 1- Aksiyon & 9- Spor \\
2- Macera & 10- Mecha \\
3- Çocuk & 11- Ecchi \\
4- Shounen & 12- Harem \\
5- Seinen & 13- Romantizm \\
6- Shoujo & 14- Dram \\
7- Josei & 15- Okul \\
8- Büyü & 16- Oyun \\
\hline
\end{tabular}




\begin{tabular}{|l|l|}
\hline \multicolumn{2}{|l|}{ (Tablo 3-2: Anime türlerinin sayısal karş1lıları) } \\
\hline 1- Aksiyon & 22- Oyun \\
2- Arabalar & 23- Parodi \\
3- Askeri & 24- Polisiye \\
4- Bilim Kurgu & 25- Psikolojik \\
5- Büyü & 26- Romantizm \\
6- Çocuklar & 27- Samuray \\
7- Doğaüstü Güçler & 28- Seinen \\
8- Dövüş Sanatları & 29- Şeytanlar \\
9- Dram & 30- Shoujo \\
10- Ecchi & 31- Shoujo Ai \\
11- Fantastik & 32- Shounen \\
12- Gerilim & 33- Shounen Ai \\
13- Gizem & 34- Şizofreni \\
14- Harem & 35- Spor \\
15- Josei & 36- Süper Güçler \\
16- Komedi & 37- Tarihi \\
17- Korku & 38- Uzay \\
18- Macera & 39- Vampir \\
19- Mecha & 40- Yaoi \\
20- Müzik & 41-Yaşamdan Kesitler \\
21- Okul & 42- Yuri \\
\hline
\end{tabular}

Verilen ilk 5 Anime haricinde belirtilen Animeleri de işleme aldık. turkanime.tv internet sitesinden faydalanılarak ankette belirtilmiş olunan her Anime ismine karşılık gelen türleri belirtilen sayısal karşılıklarına dönüştürdük. Her bir sayısal karşılığı virgül(,) ile ayırarak ve başlangıç ve bitiş işareti olarak elde edilen değerin başına ve sonuna virgül(,) ekleyerek mevcut Animenin bulunduğu hücreye yazdık. Örneğin; , 1,2, .

Kullandığımız veri tabanının 'Ş' ve 'Ç' harflerini sırası ise ' $S$ ' ve 'C' şeklinde kabul etmesi sebebi ile alfabetik siralamada bozulmalar mevcuttur.

Anket sonuçlarına göre 1984-2002 tarihleri arasında doğmayanlar, cevapsız veya istenilen tür dışında cevap verenler ve Tek Katmanlı apriori sonucu oluşan tekrarlı veriler ile ilgili satırları sildik.

\subsection{Sayısal Veri Tabloları}

Formül 2.2'ye göre güven değerlerini aşağıdaki şekillerde bulduk. 3.2.1 ve 3.2.2 de kullandığımız $\{1\} \rightarrow\{2,3\}$ şeklindeki gösterim 1 numaralı türü izleyenin 2 ve 3 numaralı türleri de izleme olasılığ olduğunu göstermektedir.

\subsubsection{Tek Katmanlı Apriori}

Veri temizleme yapıldıktan sonra en çok tekrar eden 10 anime türü ve tekrar sayısını ve "Tek Katmanlı Apriori” algoritmasında destek değeri 176 için bulunan küme ve formül 2.2'ye göre güven değerleri tablolarını aşağıdaki gibi bulmaktayız; 
International Journal of Scientific and Technological Research

ISSN 2422-8702 (Online), DOI: 10.7176/JSTR/5-7-13

Vol.5, No.7, 2019

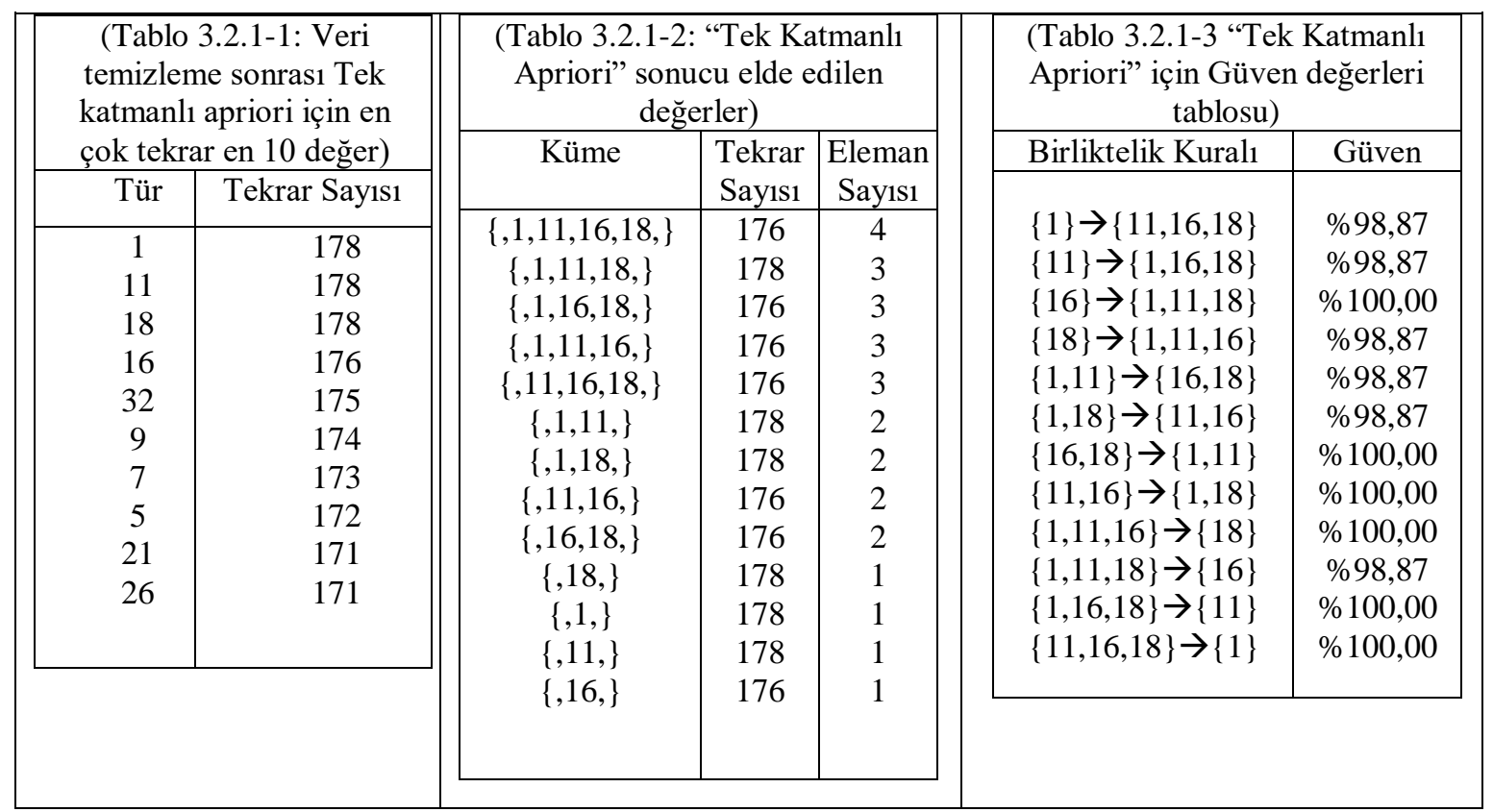

\subsection{2.İki Katmanlı Apriori}

Destek değeri 3 için sonuçlar.

1. Aşama sonuçları için Veri Temizle işlemi yapılmış 'apriori' sütunu ve 2. Aşama için destek değeri 3 koşulunu sağlayan küme ve formül 2.2'ye göre güven değeri tablolarını aşağıdaki gibi bulmaktayız;

\begin{tabular}{|c|c|c|c|c|c|}
\hline $\begin{array}{l}\text { (Tablo 3.2.2-1: Veri Temizle } \\
\text { işlemi yapılmış 'apriori' } \\
\text { sütunu -25 veri-) }\end{array}$ & \multicolumn{3}{|c|}{$\begin{array}{l}\text { (Tablo 3.2.2-2: 2. Aşama } \\
\text { sonuçları) }\end{array}$} & \multicolumn{2}{|c|}{$\begin{array}{l}\text { (Tablo 3.2.2-3: İki Katlı } \\
\text { Apriori 2. Aşama için güven } \\
\text { değerleri tablosu) }\end{array}$} \\
\hline \multirow{23}{*}{$\begin{array}{l}\{, 1,11,16,\} \\
\{, 1,11,16,18,\} \\
\{, 1,11,16,26,\} \\
\{, 1,11,18,\} \\
\{, 1,11,18,26,\} \\
\{, 1,11,18,32,\} \\
\{, 1,16,\} \\
\{, 1,18,\} \\
\{, 1,18,32,\} \\
\{, 1,3,\} \\
\{, 1,4,\} \\
\{, 1,5,11,32,\} \\
\{, 1,7,\} \\
\{, 1,7,11,\} \\
\{, 1,7,11,32,\} \\
\{, 1,7,16,\} \\
\{, 1,7,18,\} \\
\{, 1,7,9\} \\
\{, 1,9,\} \\
\{, 11,16,18,\} \\
\{, 14,16,21,26,\} \\
\{, 16,21,26,\} \\
\{, 16,21,32,\} \\
\{, 7,11,\} \\
\{, 9,21,26,\}\end{array}$} & $\{, 1,11,18$ & $\begin{array}{l}4 \\
3\end{array}$ & 3 & $\begin{array}{l}\text { Birliktelik } \\
\text { Kuralı }\end{array}$ & Güven \\
\hline & $\{, 1,11,16$ & $\begin{array}{l}3 \\
9\end{array}$ & $\begin{array}{l}3 \\
2\end{array}$ & & \\
\hline & & 7 & 2 & $\{1\} \rightarrow\{11,18\}$ & $\% 21,05$ \\
\hline & $\{, 1,11\}$, & 6 & 2 & $\{11\} \rightarrow\{1,18\}$ & $\% 36,36$ \\
\hline & $\{, 1,18\}$, & 5 & 2 & $\{18-\} \rightarrow\{1,11\}$ & $\% 50,00$ \\
\hline & $\{, 1,7\}$, & 5 & 2 & $\{1,11\} \rightarrow\{18\}$ & $\% 44,44$ \\
\hline & $\{, 1,16\}$, & 4 & 2 & $\{1,18\} \rightarrow\{11\}$ & $\% 54,14$ \\
\hline & $\{, 11,18\}$, & 4 & 2 & $\{11,18\} \rightarrow\{1\}$ & $\% 80,00$ \\
\hline & $\{, 1,32\}$, & 3 & 2 & $\{1\} \rightarrow\{11,16\}$ & $\% 15,78$ \\
\hline & $\{, 11,16\}$, & 3 & 2 & $\{11\} \rightarrow\{1,16\}$ & $\% 27,27$ \\
\hline & $\{, 11,32\}$, & 3 & 2 & $\{16\} \rightarrow\{1,11\}$ & $\% 33,33$ \\
\hline & $\{, 7,11\}$, & 3 & 2 & $\{1,11\} \rightarrow\{16\}$ & $\% 33,33$ \\
\hline & $\{, 16,26\}$, & 19 & 1 & $\{1,16\} \rightarrow\{11\}$ & $\% 60,00$ \\
\hline & $\{, 21,26\}$, & 11 & 1 & $\{11,16\} \rightarrow\{1\}$ & $\% 75,00$ \\
\hline & $\{, 1\}$, & 9 & 1 & & \\
\hline & $\{, 11\}$, & 8 & 1 & & \\
\hline & $\{, 16\}$, & 7 & 1 & & \\
\hline & $\{, 18\}$, & 5 & 1 & & \\
\hline & $\{, 7\}$, & 4 & 1 & & \\
\hline & $\{, 26\}$, & & & & \\
\hline & $\{, 21\}$, & & & & \\
\hline & & & & & \\
\hline & & & & & \\
\hline
\end{tabular}




\subsubsection{Sonuçların Karşılaştırılması}

\begin{tabular}{|c|c|}
\hline \multicolumn{2}{|c|}{$\begin{array}{l}\text { (Tablo 3.3.2-1 “Tek Katmanlı Apriori” için Güven değerleri } \\
\text { tablosu) }\end{array}$} \\
\hline Birliktelik Kuralı & Güven \\
\hline $\begin{array}{l}\{\text { Aksiyon, Komedi, Macera }\} \rightarrow\{\text { Fantastik }\} \\
\{\text { Fantastik, Komedi, Macera }\} \rightarrow\{\text { Aksiyon }\} \\
\{\text { Komedi, Macera }\} \rightarrow\{\text { Aksiyon, Fantastik }\} \\
\{\text { Fantastik, Komedi }\} \rightarrow\{\text { Aksiyon, Macera }\} \\
\{\text { Aksiyon, Fantastik, Komedi }\} \rightarrow\{\text { Macera }\} \\
\{\text { Komedi }\} \rightarrow\{\text { Aksiyon, Fantastik, Macera }\} \\
\{\text { Aksiyon }\} \rightarrow\{\text { Fantastik, Komedi, Macera }\} \\
\{\text { Fantastik }\} \rightarrow\{\text { Aksiyon, Komedi, Macera }\} \\
\{\text { Macera }\} \rightarrow\{\text { Aksiyon, Fantastik, Komedi }\} \\
\{\text { Aksiyon, Fantastik }\} \rightarrow\{\text { Komedi , Macera }\} \\
\{\text { Aksiyon, Macera }\} \rightarrow\{\text { Fantastik, Komedi }\} \\
\{\text { Aksiyon, Fantastik, Macera }\} \rightarrow\{\text { Komedi }\}\end{array}$ & $\begin{array}{l}\% 100,00 \\
\% 100,00 \\
\% 100,00 \\
\% 100,00 \\
\% 100,00 \\
\% 100,00 \\
\% 98,87 \\
\% 98,87 \\
\% 98,87 \\
\% 98,87 \\
\% 98,87\end{array}$ \\
\hline
\end{tabular}

\begin{tabular}{|l|l|}
\hline \multicolumn{2}{|l|}{$\begin{array}{l}\text { Tablo 3.2.3-2: İki Katlı Apriori 2. Aşama için güven } \\
\text { değerleri tablosu) }\end{array}$} \\
\hline Birliktelik Kuralı & Güven \\
\hline$\{$ Fantastik, Macera $\} \rightarrow\{$ Aksiyon $\}$ & $\% 80,00$ \\
$\{$ Fantastik, Komedi $\} \rightarrow\{$ Aksiyon $\}$ & $\% 75,00$ \\
$\{$ Aksiyon, Komedi $\} \rightarrow\{$ Fantastik $\}$ & $\% 60,00$ \\
$\{$ Aksiyon, Macera $\} \rightarrow\{$ Fantastik $\}$ & $\% 54,14$ \\
$\{$ Macera $\} \rightarrow\{$ Aksiyon, Fantastik $\}$ & $\% 50,00$ \\
$\{$ Aksiyon, Fantastik $\} \rightarrow\{$ Macera $\}$ & $\% 44,44$ \\
$\{$ Fantastik $\} \rightarrow\{$ Aksiyon, Macera $\}$ & $\% 36,36$ \\
$\{$ Komedi $\} \rightarrow\{$ Aksiyon, Fantastik $\}$ & $\% 33,33$ \\
$\{$ Aksiyon, Fantastik $\} \rightarrow\{$ Komedi $\}$ & $\% 33,33$ \\
$\{$ Fantastik $\} \rightarrow\{$ Aksiyon, Komedi $\}$ & $\% 27,27$ \\
$\{$ Aksiyon $\} \rightarrow\{$ Fantastik, Macera $\}$ & $\% 21,05$ \\
$\{$ Aksiyon $\} \rightarrow\{$ Fantastik, Komedi $\}$ & $\% 15,78$ \\
& \\
\hline
\end{tabular}

Tek Katmanlı Apriori sonucuna göre 1,11,16,18 arasında yüksek güven değeriyle ilişki olduğu görmekteyiz. Ama İki Katmanlı Apriori sonucunda 16 ve 18 arasında bir ilişki olmadığı ve 16nın 18e göre 1 ve 11 ile daha zayıf bir ilişkisi olduğunu görmekteyiz. Yani 1,11 ve 18 arasında bir ilişki 1,11 ve 16 arasında bir ilişki olmak üzere iki farklı ilişki olduğu görülmektedir.

\section{Sonuç}

Türe göre Anime seçiminin sonuçlarında yani "Tek Katmanlı Apriori”de 1,11,16,18 numaralı türler arasında \%98,87 ve \%100,00 güven değerlerinde olduğu görülmüştür. Kişisel tercihlere göre Anime seçiminde yani “İki Katmanlı Apriori”de 1,11,16 ve 1,11,18 tür grupları arasında sırası ise \% 15,78-75,00 ve \%21,05-80,00 güven değerleri arasında bir dalgalanma görülmüştür.

1,11,16 ve 1,11,18 tür gruplarının ayrı olmalarının sebebi “Tek Katmanlı Apriori”den farklı olarak 16 ve 18 numaralı türlerin birbirleri ile doğrudan ilişkilerinin bulunmadığı anlamına gelmektedir. Daha basit bir tanımla 1 ve 11 numaralı türlere sahip Anime izleyenlerin 16 ve 18 numaralı türlerin bir arada bulunduğu Animeleri izlemedikleri veya 16 ve 18 numaralı türlerden birinin bulunduğu Animeyi izleyenlerin 1 ve 11 numaralı türlerinde Animede bulunmasını tercih ettikleri anlamına gelmektedir.

Toparlamak gerekirse türe göre Anime seçimi yapanların 1 ve 11 numaralı türlerin bulunduğu Animeler izlenirken aynı zamanda 16 ve 18 numaralı türlerinde birlikte bulunduğu Animeler de izlenmektedir çıkarımı güvenilir bir sonuç değildir. Bunun yerine 1 ve 11 numaralı türlerin bulunduğu Animeler 
izlenirken aynı zamanda 16 veya 18 numaralı türlerden yalnız birinin bulunduğu Animeler de izlenmektedir çıkarımı daha tutarlı bir birliktelik kuralı oluşturmamızı sağlamaktadır.

\section{Kaynakça}

1. http://www.anime.gen.tr/yazi.php?id=44 (Mart 2017)

2. https://kotaku.com/what-anime-means-1689582070 (Kasim 2017)

3. Er, E. Gülay. "Siberkültürde Bedenin Görsel Sunumu: Serıal Experıments Laın Adlı Anime Üzerine Bir Çözümleme." İstanbul Üniversitesi Iletişim Fakültesi Dergisi| Istanbul University Faculty of Communication Journal 1.36 (2009): 71-91.

4. Kilıçarslan, Y.- Uşak Üniversitesi İletişim Fakültesi, Radyo Televizyon Sinema Bölümü Uluslararası Sosyal Araştırmalar Dergisi cilt:9 sayı:43 Nisan 2016 ISSN: 1307-9581

5. Alicenap Taş, Çiğdem."Yerelden evrensele japon anime ve manga sanatı." Anadolu Üniversitesi Sanat ve Tasarım Dergisi 7.7: 31-60

6. Öz, Melodi İpek. Japon Bilim Kurgu Animelerinde Kent Ve Mimarllk: Ghost In The Shell I\&u Ve Metropolıs Animeleri Üzerinden Bir Inceleme. Diss. Fen Bilimleri Enstitüsü, 2013.

7. Agrawal, Rakesh, and Ramakrishnan Srikant. "Fast algorithms for mining association rules." Proc. 20th int. conf. very large data bases, VLDB. Vol. 1215. 1994.

8. Hand, David J. "Data Mining." Encyclopedia of Environmetrics 2, Print ISBN : 9780471899976 , Online ISBN: 9780470057339 , DOI: 10.1002/9780470057339 (2006).

9. Özkan, Y. "Veri Madenciliği Yöntemleri, Papatya Yayıncılık ve Eğitim AŞ." İstanbul, Türkiye, 2016, ISBN: 9756797822, 3. Bask1 .

10. Mining Data, J. Han, M. Kamber, "Data mining concepts and techniques", MorganKaufinann ( http://liacs.leidenuniv.nl/ bakkerem2/dbdm2007/05_dbdm2007_Data\%20Mining.pdf ) (2006).

11. Karabatak, M ve İnce, M. C., “Apriori Algoritması ile Öğrenci Başarısı Analizi”, Eleco’ 2004 Elektrik-Elektronik ve Bilgisayar Mühendisleri Sempozyumu”,Bursa, (2004).

12. Han, Jiawei, Jian Pei, and Micheline Kamber. Data mining: concepts and techniques. Elsevier, 2011, ISBN-13: 978-9380931913. 